\title{
Correlation between Climate Factors and Vegetation Cover in Qinghai Province, China
}

\section{Yousif Elnour Yagoub ${ }^{1,2,3^{*}}$, Zhongqin Li1 ${ }^{1}$ Omer Said Musa ${ }^{2}$, Muhammad Naveed Anjum ${ }^{4}$, Feiteng Wang1, Yanqun Bi1, Bo Zhang3}

\author{
${ }^{1}$ State Key Laboratory of Cryospheric Sciences/Tian Shan Glaciological Station, Northwest Institute of Eco-Environment and \\ Resources, CAS, Lanzhou, China \\ ${ }^{2}$ Department of Forest Protection and Conservation, Faculty of Forestry, University of Khartoum, Shambat, Sudan \\ ${ }^{3}$ College of Geography and Environmental Science, Northwest Normal University, Lanzhou, China \\ ${ }^{4}$ Division of Hydrology Water-Land Resources, Northwest Institute of Eco-Environment and Resources, CAS, Lanzhou, China \\ Email: *yousif@lzb.ac.cn, *yousifelnouryagoub@yahoo.com
}

How to cite this paper: Yagoub, Y.E., Li, Z.Q., Musa, O.S., Anjum, M.N., Wang, F.T., Bi, Y.Q. and Zhang, B. (2017) Correlation between Climate Factors and Vegetation Cover in Qinghai Province, China. Journal of Geographic Information System, 9, 403-419.

https://doi.org/10.4236/jgis.2017.94025

Received: May 27, 2017

Accepted: July 18, 2017

Published: July 24, 2017

Copyright ( 92017 by authors and Scientific Research Publishing Inc. This work is licensed under the Creative Commons Attribution-NonCommercial International License (CC BY-NC 4.0).

http://creativecommons.org/licenses/by-nc/4.0/ (c) (i) \&) Open Access

\begin{abstract}
The Qinghai Province, situated in the northwest of China, is experiencing a continuous warming which is approximately three times more than the rate of global warming. This ongoing warming has a direct connection to vegetation cover, with significant societal and economic impacts in this region. In the present study, we investigate the correlation between climate change and vegetation cover in Qinghai Province. Analysis shows that in the Qinghai Province, order of NDVI is highest in summer followed by autumn, spring and winter. By calculating the average annual and seasonal-NDVI values, it is deduced that the main type of vegetation cover in the Qinghai Province has an upward trend at the rate of 0.013/10a, 0.016/10a, 0.035/10a and 0.058/10a for annual, winter, spring and summer, respectively. While a downward trend at a rate of $0.056 / 10 \mathrm{a}$ is present in autumn-NDVI. At the $0.01 \%$ significance level, a significant positive relationship of winter-NDVI with mean winter precipitation and temperature is revealed. Mean NDVI of spring and autumn show a significant positive relationship with respective seasonal mean precipitation. However, a significant difference is present between mean summer-NDVI and mean summer precipitation. Furthermore, mean NDVI of summer and autumn has a significant negative relationship with respective seasonal mean temperature.
\end{abstract}

\section{Keywords}

Land Cover Change, Climate Factors, NDVI, Qinghai Province 


\section{Introduction}

Global mean temperature has increased by $0.85^{\circ} \mathrm{C}$ over the period of 1880 to 2012 and this increase in temperature is likely due to anthropogenic activities that have increased the concentrations of greenhouse gases to unprecedented levels [1]. Over the last 50 years, the Qinghai Province of China is experiencing a continuous warming which is approximately three times more than the global warming rate. The increasing trend in temperature is one of the main reasons for climate change which consequently lead to droughts and negative effects on vegetation cover due to the increase in evapotranspiration in Qinghai Province [2]. A plausible warmer world with longer and more severe droughts could lead to rapid collapse of tropical forest communities converting them from a net carbon sink to a large carbon source with cascading ecosystem effects affecting global climate-vegetation feedbacks [3]. Due to the monsoon climate interacted with the complicated geographical landscapes; high-frequency severe droughts are the most devastating natural disasters in China. According to statistics, the drought affected and damaged areas have greatly increased in the past 50 years [4]. In the 2000s, extreme droughts occurred frequently in China, for example, the winter-spring drought in southwest China during 2009-2010 [5] and the spring-summer drought over the middle and lower reaches of Yangtze River in 2011 [6]. The drought has especially affected the agricultural areas in northern China [7]. The regional geological, geomorphologic and ecological systems are complex and diverse. These natural factors and climate change are intertwined, making regional economic and social developments extremely challenging. The regional economic community has demonstrated a high degree of sensitivity to these changes. The literature shows that there has been a significant warming trend in Northwest China since 1951 [8]. Thus, droughts are difficult to pinpoint in time and space since it is very complex to identify the moment when a drought starts and ends, and also to quantify its duration, magnitude and spatial extent [9]. China is on the top in the world in paddy rice, wheat and fresh vegetable production. In total, China ranks number 1 in the world in the production of 45 agricultural commodities [10]. Series of geological disasters and environmental problems of agricultural biological disasters in the Qinghai Province will consequently influence the societal and economic conditions [11]. Global climate change and anthropogenic activities are the main driving forces of terrestrial ecosystems [12]. The quantitative evaluation of direct economic loss of the grassland and livestock due to drought and snow disaster comes true. The evaluation model is in line with grass pasture growth law and livestock production characteristics. The evaluation is accord with the actual loss of animal husbandry. Therefore, the evaluation can be used in the grassland animal husbandry assessment [13]. China has about 328 million people involved in agricultural labour, and a vast majority of them are small and marginal farmers (operating 0.4 ha on average). Further, the vast majorities of farmers depend on rain-fed crops and are, therefore, particularly vulnerable to the vagaries of the climate. The government of China $(\mathrm{GoC})$ recognizes the importance of revitalizing the agri- 
cultural insurance industry to meet the needs of farmers throughout China in a better way [14]. The Department of Crop Production and Ministry of Agriculture in China have initiated schemes having significant contributions in anti-disaster and disaster relief. The agricultural sectors have strengthened monitoring and early warning of disasters [15].

The aim of this study is to investigate the relationship between climate factors (precipitation and temperature) and vegetation cover in Qinghai Province of China over the period of 2001 to 2013.

\section{Material and Methods}

\subsection{Study Area}

Figure 1 shows the geographical location and topography of Qinghai Province. This province has a large variety of ecosystems, from the sub-tropical rain forest in the south-east to the alpine desert in the north-west. Among all types of land cover vegetation, alpine grassland is the dominant ecosystem, combined cover an area of $715823.8 \mathrm{~km}^{2}$, extending from the latitude of $31^{\circ} 40^{\prime}-39^{\circ} 30^{\prime} \mathrm{N}$ and longitude of $89^{\circ} 25^{\prime}-103^{\circ} 04^{\prime} \mathrm{E}$ and altitude $1721-8500 \mathrm{~m}$. The total irrigated areas in Qinghai Province, as reports in [16] are $259.3\left(10^{3} \mathrm{ha}\right)$ out of which $182.4\left(10^{3} \mathrm{ha}\right)$ is effective irrigated area, $31.2\left(10^{3} \mathrm{ha}\right)$ is woodland area, $6.8\left(10^{3}\right.$ ha) orchard area, $38.9\left(10^{3} \mathrm{ha}\right)$ is pasture land and $155\left(10^{3} \mathrm{ha}\right)$ is actual effective irrigated area, respectively. The major economic indices are number of enterprises, employment in the year (person), business income (10 $\left.0^{3} \mathrm{RMB}\right)$ and Tax payment ( $\left.10^{3} \mathrm{RMB}\right): 20,2966,1273$ and 1035 , respectively.

\subsection{Normalized Difference Vegetation Index (NDVI)}

In this research, we utilize the MODIS data of 16-day temporal and $250 \mathrm{~m}$ spatial resolution (MOD13Q1, collection 5), for period of 2001-2013. This data is obtained from NASA website

(ftp://ladsweb.nascom.nasa.gov/allData/5/MOD13Q1). This data maintains by the NASA in Land Processes Distributed Active Archive Center (LP DAAC) at the USGS/Earth Resources Observation and Science (EROS) Centre. A vegetation index is an indicator that describes the greenness, relative density and health of vegetation for each picture element (pixel). Although there are several vegetation indices, NDVI is one of the most widely used vegetation indices and its range varies from 1.0 to -1.0 . More details of NDVI and its utilization can be found in [17].

\subsection{Linear Trend (Slope)}

Analysis of linear regression trend is carried out by using ArcGIS v 10.2 Software, which can simulate trends in each grid [18]. ArcGIS can be used to reflect different periods of vegetation cover characteristics. In this study, the relative slope, in Formula (1), is used to indicate the relative NDVI change in every pixel point. 

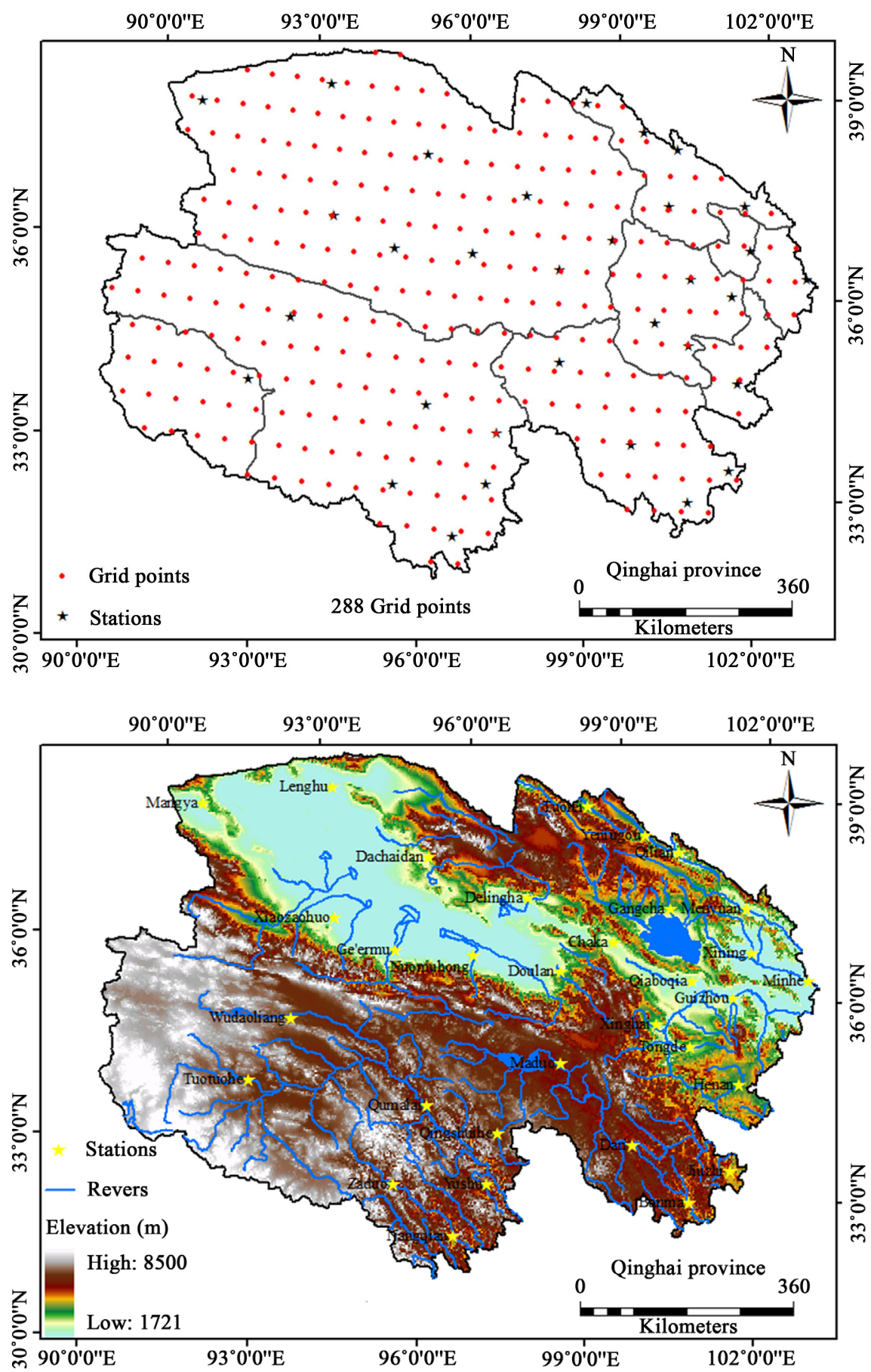

Figure 1. The distribution of meteorological stations and grid points of climate data in Qinghai Province.

$$
\theta_{\text {Slope }}=\frac{n \times \sum_{i=1}^{n}{ }_{i} \mathrm{NDVI}_{i}-\sum_{i=1}^{n} i \sum_{i=1}^{n} \mathrm{NDVI}_{i}}{n \times \sum_{i=1}^{n} i^{2}-\left(\sum_{i=1}^{n} i\right)^{2}}
$$

where $i$ is the annual number; $\mathrm{n}$ is monitoring period (the cumulative number of years); NDVI as NDVI mean value of the $i$ year; slope is each pixel NDVI trend of the slope, if $\theta_{\text {Slope }}>0$ then the pixel NDVI value in $n$ years is increasing, 
otherwise it is decreasing. This study categorizes into a significant increase, slight increase, essentially the same, slightly reduced and a significant reduction, and the statistics of the study area in 2001-2013 vegetation changes and the percentage of each class area.

\subsection{Correlation}

It is possible to explain the closeness of a relationship between geographic features, and closely related to the degree of mutual determination between geographical elements, mainly through the correlation coefficient calculation. In this research, study of NDVI correlation with average annual temperature and precipitation is carried out by-pixel spatial correlation, the correlation coefficient used to reflect the sequence of climatic factors and NDVI degree of correlation, the range of correlation coefficient varies from -1 to 1 . Formula is given as below:

$$
r_{x y}=\frac{\sum_{i=1}^{n}\left(x_{i}-\bar{x}\right)\left(y_{i}-\bar{y}\right)}{\sqrt{\sum_{i=1}^{n}\left(x_{i}-\bar{x}\right)^{2} \sum_{i=1}^{n}\left(y_{i}-\bar{y}\right)^{2}}}
$$

where: $n$ is the number of time series, $x$ and $y$ are two elements of the correlation, and represent the average of the two elements of the sample values, and finally delineated thresholds based on the number of data, the results of the correlation level of significant.

\section{Result and Discussions}

Figure 2 shows the vegetation on the monthly average time scale in the Qinghai Province, the NDVI value distribution show that May to August are the center to both sides of vegetation cover in a year, which corresponds to the average monthly vegetation NDVI values: $0.12,0.12,0.13,0.15,0.26,0.35,0.36,0.28$, $0.15,0.12,0.12$ and 0.12 for January to December, respectively. Overall, the rainy season (April to September) has higher vegetation covers.

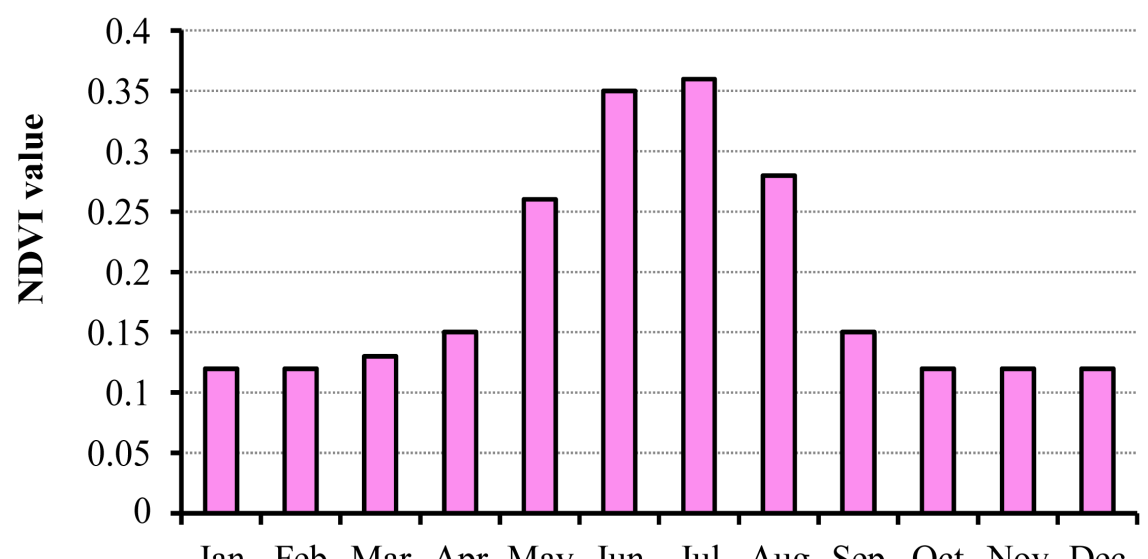

Figure 2. The distribution of the mean monthly-NDVI in Qinghai Province over the period of 2001-2013. 


\subsection{Spatial Distribution of Vegetation}

Spatial distribution of mean NDVI in Qinghai Province is shown in Figure 3 which clearly exhibits the mean annual and seasonal-NDVI, a high value is in the eastern and southern part of the Qinghai Province. The vegetation cover is
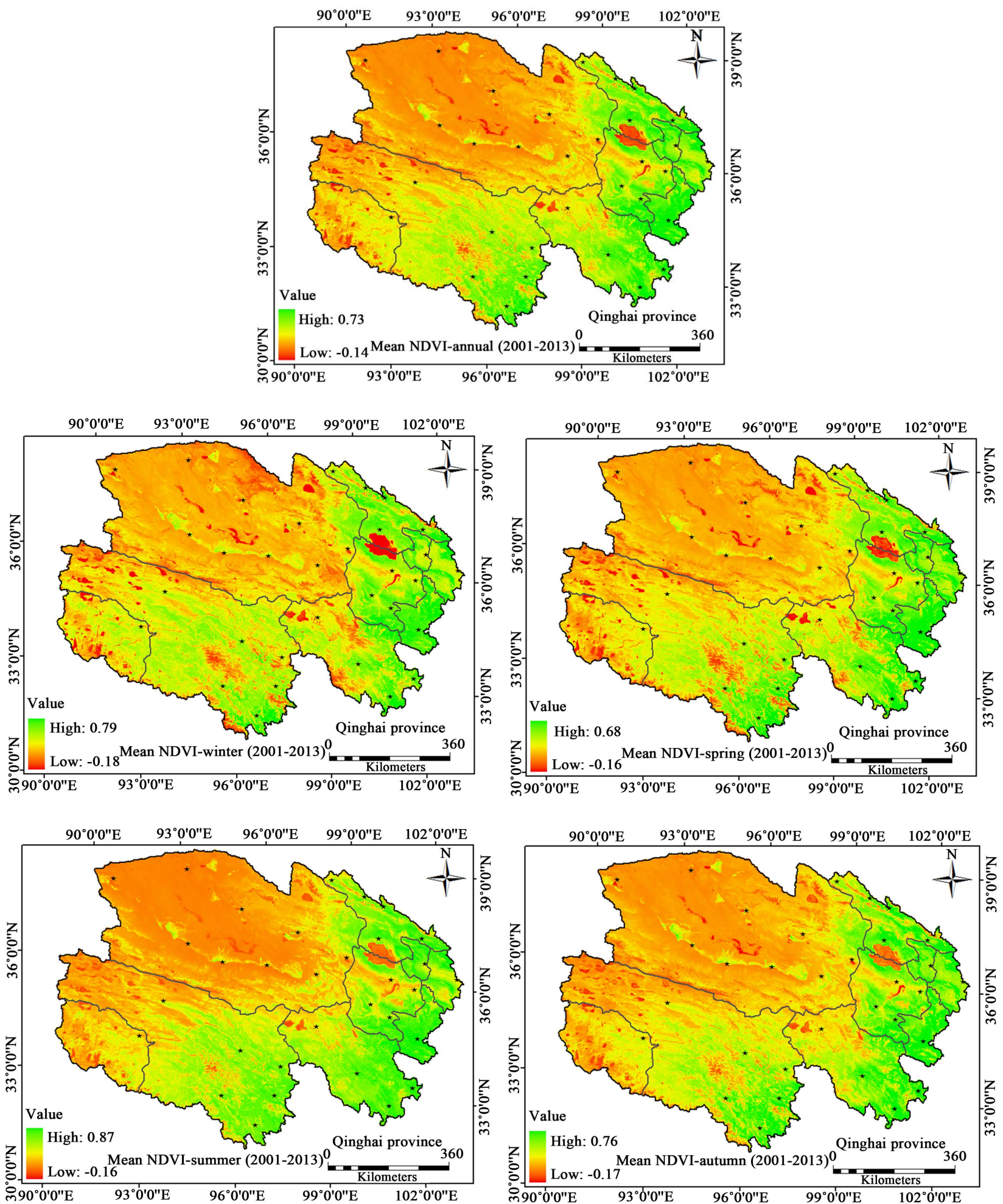

Figure 3. Spatial distribution of mean annual and seasonal-NDVI in Qinghai Province over the period of 2001-2013. 
high in the eastern and southern part due to humid climate zone. The vegetation cover is widely distributed in woodland, grasslands and crop land. The northwest part has a low vegetation cover value due to the location in the desert area which is covered by rock and sands with low precipitation.

Figure 4 shows the calculation of NDVI; each season of the Qinghai Province is ranked on the basis of NDVI. Summer season has the highest NDVI followed by autumn, spring and winter. Analysis of average annual and seasonal-NDVI shows that the main vegetation cover type in the Qinghai Province has an upward trend at the rate of 0.013/10a, 0.016/10a, 0.035/10a and 0.058/10a for annual, winter, spring and summer, respectively. While an autumn-NDVI has downward trend at a rate of 0.056/10a. The plain and other highland mountain areas have different values due to seasonal differences in the degree of green crops and woodland, grassland due to seasonal changes in climate factors. [13] analyzed and investigated the data of pasture, precipitation and disaster monitoring in 20 grassland ecological monitoring sites in Qinghai Province from 2003 to 2011 .They found that, at $0.001 \%$ significance level, grassland herbage yield and precipitation have a close relationship. A good correlation is found between the forage yield at the end of August and the precipitation from May to August. However, a decline in 2009-NDVI is found due to the increase in precipitation in that particular year, as reports on the website of China Statistical Information Network: http://www.tjcn.org/help/3574.html. In 2009, the prices of agricultural production materials decline to $2.2 \%$ compared with the previous year. Producer Price Index (PPI) declined to 8.7\%. [13] reported that the snow disasters in December 2008 in Doulan (middle part of Qinghai Province) cause the death of livestock which is $0.11 \%$ of the total Loss $\left(18,455 \times 10^{3} \mathrm{RMB}\right)$.

\subsection{Spatial Variation of Vegetation Cover}

\subsubsection{Annual}

Based on the calculation of principle $\theta$ slope value, the spatial variation is reclassified into seven categories from low to high value: significant degradation, moderate degradation, mild degradation, no change, mild improvement, moderate improvement and significant improvement. Figure 5 and Table 1 show

Table 1. Statistical result of trend of mean annual-NDVI change simulated in Qinghai Province over the period of 2001-2013.

\begin{tabular}{ccccc}
\hline & & & & \multicolumn{2}{c}{ Mean NDVI } \\
\cline { 3 - 4 } & Category & $\theta_{\text {Slope }}$ range & Area Km ${ }^{2}$ & $\%$ \\
\hline 1 & Significant degradation & $\theta<-0.035$ & 5604.8 & 0.8 \\
2 & Moderate degradation & $-0.035<\theta>-0.025$ & 8547.8 & 1.2 \\
3 & Mild degradation & $-0.025<\theta>-0.015$ & 17924.1 & 2.5 \\
4 & No change & $-0.015<\theta>0.015$ & 613070.8 & 85.6 \\
5 & Mild improvement & $0.015<\theta>0.025$ & 36475.3 & 5.1 \\
6 & Moderate improvement & $0.025<\theta>0.035$ & 22429.3 & 3.1 \\
7 & Significant improvement & $\theta>0.03$ & 11771.6 & 1.6 \\
\hline
\end{tabular}



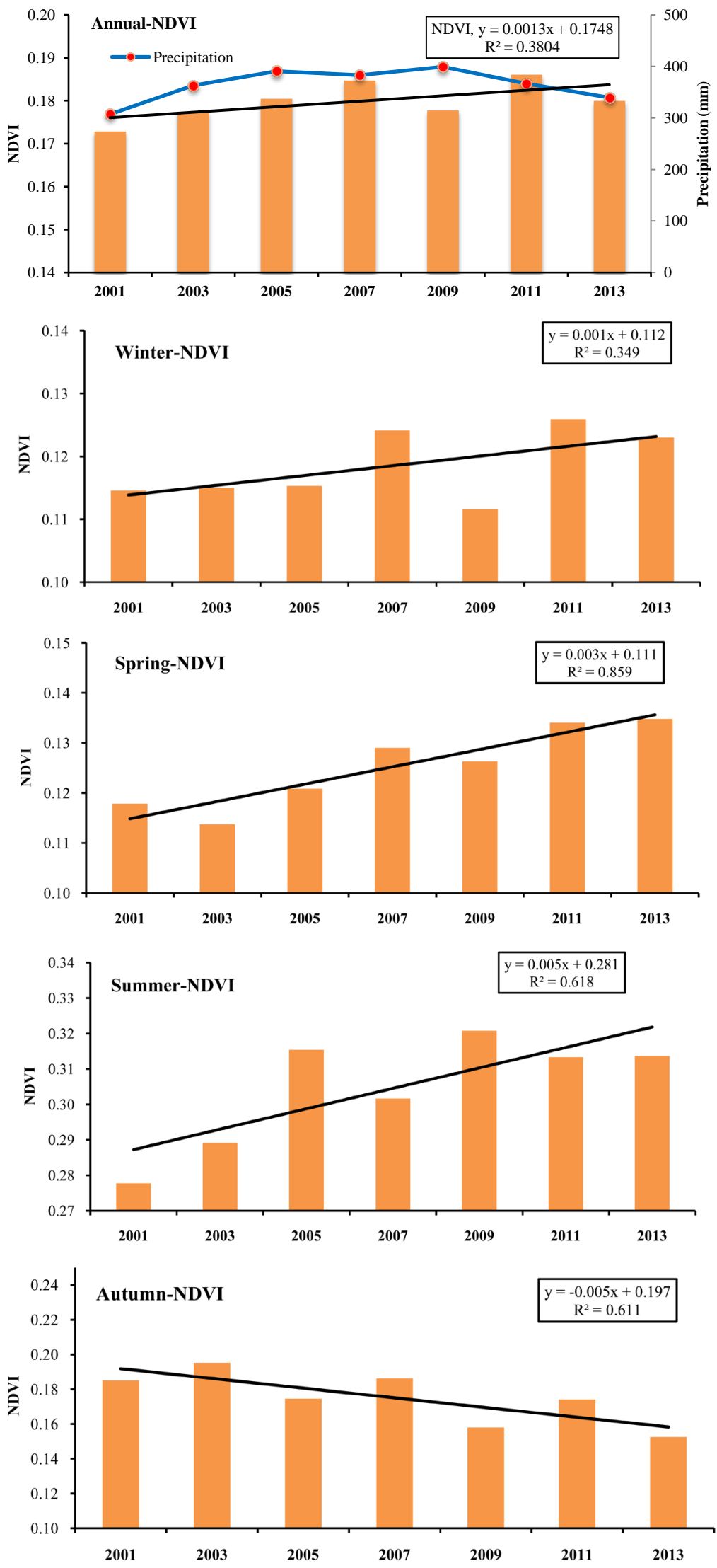

Figure 4. Trend of different vegetation types, annual and seasonal-NDVI change in Qinghai Province over the period of 2001-2013. 


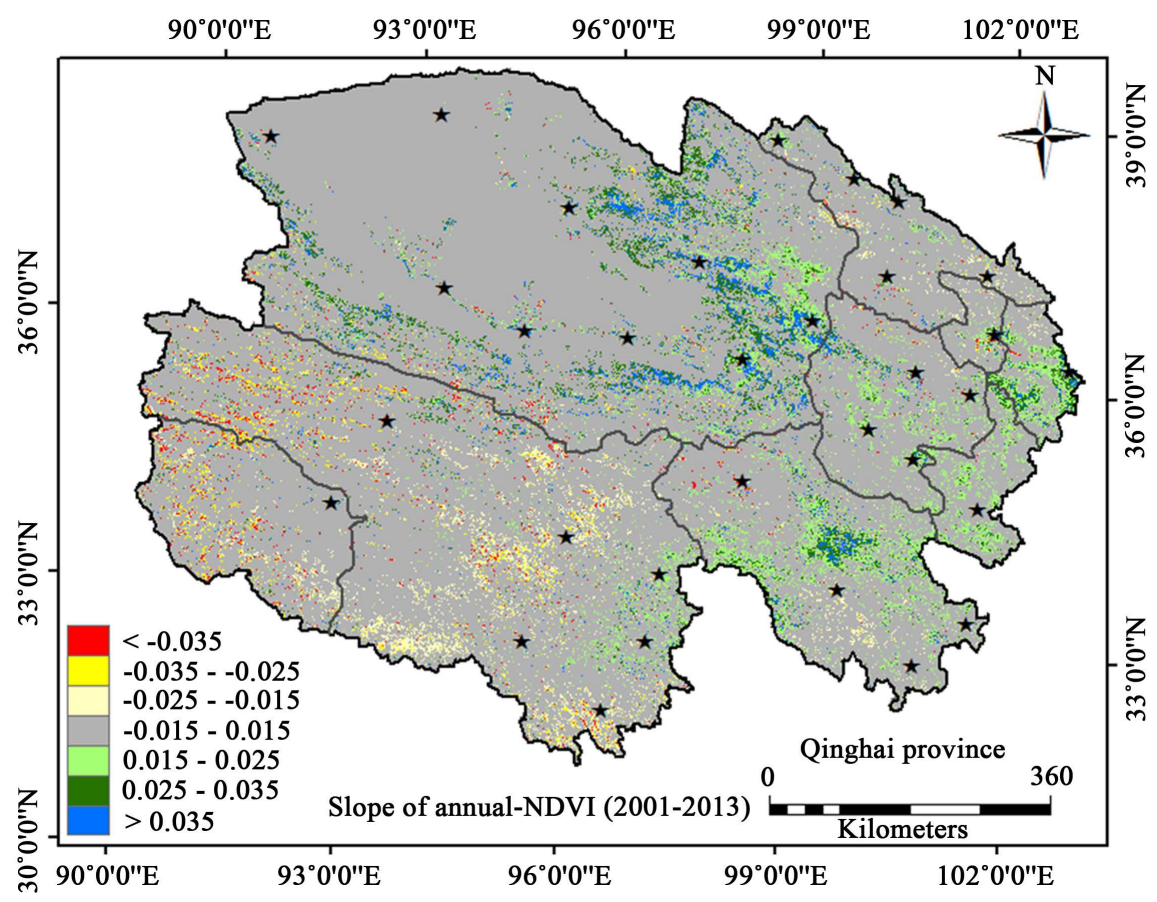

Figure 5. Temporal change characteristic of mean annual-NDVI based on the linear trend in Qinghai Province over the period of 2001-2013.

that there is generally improvement of vegetation in the southeast, the eastern and middle part of Qinghai Province, while south-wes is in under degradation. The order of spatial variation of vegetation cover is: significant degradation (an area of $5604.8 \mathrm{~km}^{2}$ accounts $0.8 \%$ of the total area, moderate degradation (an area of $8547.8 \mathrm{~km}^{2}$ accounts $1.2 \%$ of the total area), mild degradation (an area of $17,924.1 \mathrm{~km}^{2}$ accounts $2.5 \%$ of the total area), no change (an area of $613,070.8$ $\mathrm{km}^{2}$ accounts $85.6 \%$ of the total area), mild improvement (an area of $36,475.3$ $\mathrm{km}^{2}$ accounts $5.1 \%$ of the total area), moderate improvement (an area of 22,429.3 $\mathrm{km}^{2}$ accounts $3.1 \%$ of the total area) and significant improvement (an area of $11,771.6 \mathrm{~km}^{2}$ accounts $1.6 \%$ of the total area).

\subsubsection{Seasonal}

Using a linear regression analysis, mean seasonal vegetation cover in Qinghai Province is calculated from 2001-2013, spatial reclassification is divided into seven categories: significant degradation; moderate degradation; mild degradation; no change; mild improvement; moderate improvement and significant improvement. Figure 6 and Table 2 show the spatial variation of significant degradation in the Qinghai Province means seasonal-NDVI (2.6\%, 1.7\%, 0.7\% and $19.2 \%$ of the total area in winter, spring, summer and autumn, respectively). The higher change of degradation in autumn-NDVI is locating in the southern part of northeastern Qinghai Province. A significant improvement is found depicted as $4.2 \%, 6.8 \%, 11.3 \%$ and $1.3 \%$ of the total area in winter, spring, summer and autumn, respectively. The order of improvement is spring $>$ summer $>$ winter $>$ autumn. No change is found in $79.6 \%, 74.4 \%, 61.1 \%$ and $58.4 \%$ of the total area in winter, spring, summer and autumn, respectively. [19] reported that the 

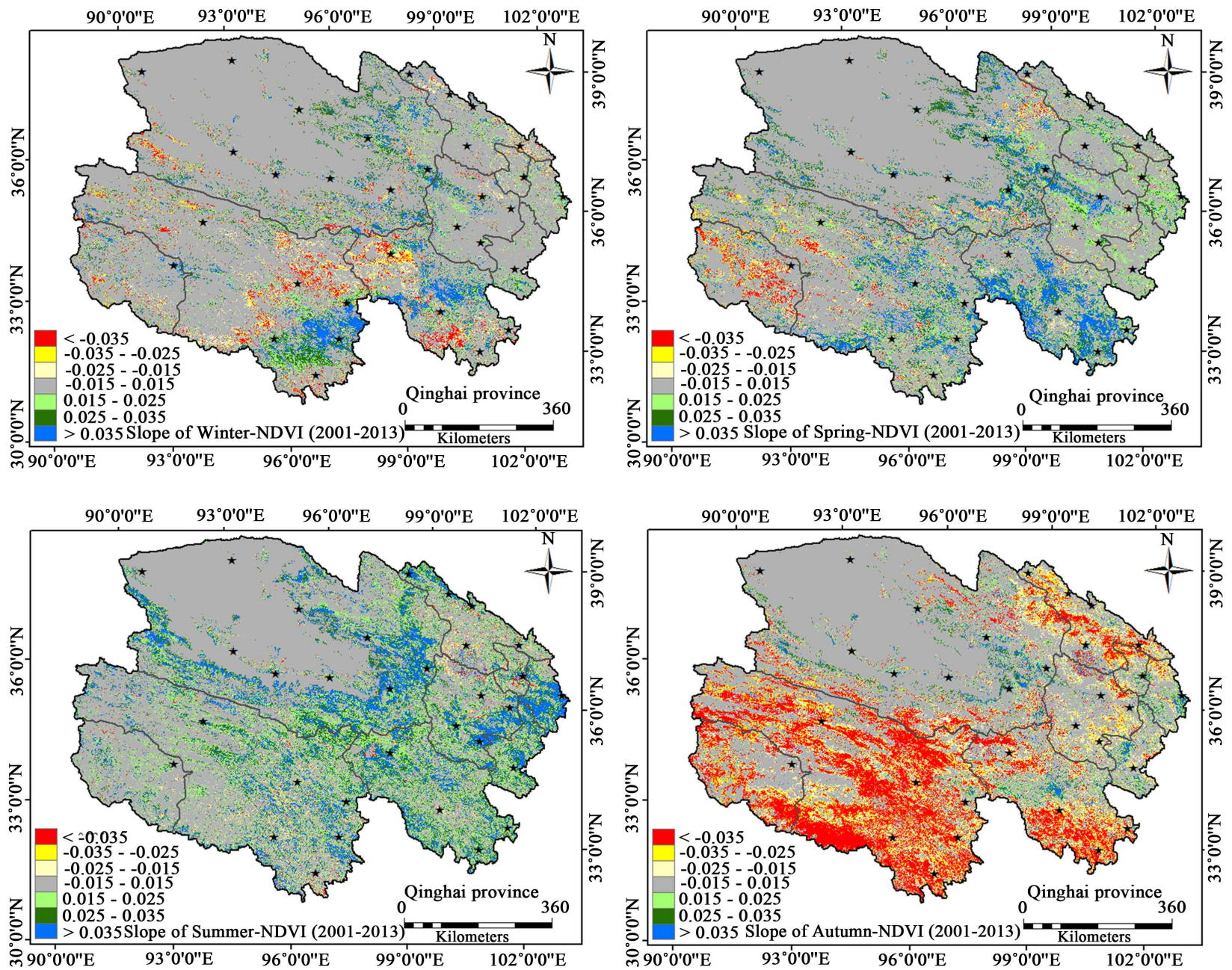

Figure 6. Spatial-temporal change characteristic of mean seasonal-NDVI based on the Slope in Qinghai Province over the period of 2001-2013.

Table 2. Statistical result of trend of mean seasonal-NDVI change simulated in Qinghai Province over the period of 2001-2013.

\begin{tabular}{|c|c|c|c|c|c|c|c|c|c|c|}
\hline & \multirow{2}{*}{ Category } & \multirow{2}{*}{$\theta_{\text {Slope }}$ range } & \multicolumn{2}{|c|}{ Winter } & \multicolumn{2}{|c|}{ Spring } & \multicolumn{2}{|c|}{ Summer } & \multicolumn{2}{|c|}{ Autumn } \\
\hline & & & Area $\mathrm{Km}^{2}$ & $\%$ & Area $\mathrm{Km}^{2}$ & $\%$ & Area $\mathrm{Km}^{2}$ & $\%$ & Area $\mathrm{Km}^{2}$ & $\%$ \\
\hline 1 & $\begin{array}{c}\text { Significant } \\
\text { degradation }\end{array}$ & $\theta<-0.035$ & $18,647.1$ & 2.6 & $12,351.3$ & 1.7 & 4870.7 & 0.7 & $137,223.7$ & 19.2 \\
\hline 2 & $\begin{array}{c}\text { Moderate } \\
\text { degradation }\end{array}$ & $-0.035<\theta>-0.025$ & $13,575.9$ & 1.9 & $12,441.0$ & 1.7 & 5259.1 & 0.7 & $58,084.6$ & 8.1 \\
\hline 3 & $\begin{array}{c}\text { Mild } \\
\text { degradation }\end{array}$ & $-0.025<\theta>-0.015$ & $18,026.6$ & 2.5 & $12,211.4$ & 1.7 & $11,956.7$ & 1.7 & $62,151.4$ & 8.7 \\
\hline 4 & No change & $-0.015<\theta>0.015$ & $569,743.6$ & 79.6 & $532,533.3$ & 74.4 & $437,078.4$ & 61.1 & $417,940.4$ & 58.4 \\
\hline 5 & $\begin{array}{c}\text { Mild } \\
\text { improvement }\end{array}$ & $0.015<\theta>0.025$ & $31,739.4$ & 4.4 & $53,193.6$ & 7.4 & $102,224.4$ & 14.3 & $16,939.9$ & 2.4 \\
\hline 6 & $\begin{array}{c}\text { Moderate } \\
\text { improvement }\end{array}$ & $0.025<\theta>0.035$ & $33,787.9$ & 4.7 & $44,542.9$ & 6.2 & $73,276.1$ & 10.2 & $13,880.8$ & 1.9 \\
\hline \multirow[t]{2}{*}{7} & $\begin{array}{c}\text { Significant } \\
\text { improvement }\end{array}$ & $\theta>0.03$ & $30,303.3$ & 4.2 & $48,550.3$ & 6.8 & $81,158.4$ & 11.3 & 9602.9 & 1.3 \\
\hline & Total & & $715,823.8$ & 100 & $715,823.8$ & 100 & $715,823.8$ & 100 & $715,823.8$ & 100 \\
\hline
\end{tabular}


2001-2011 is the period of remarkable human intervention on the alpine grassland ecosystem (fencing degrading grassland and reducing livestock number); therefore, it played a much more important role in the grassland restoration. This implies that the obvious decline in the number of livestock animals and large-scale building the fences over the Qinghai-Tibet Plateau alpine grassland in recent years relieved the grazing pressure of the rangeland.

\subsection{Relationship between Vegetation Cover and Climate Factors}

Programming in SPSS v 17 is used to calculate the correlation coefficients between NDVI and spatial variation of climate factors in Qinghai Province over the period of 2001-2013. Seasonal precipitation and temperature at each site is utilized to draw the trends of spatial distribution of precipitation and temperature (by using interpolation in ArcGIS). Figure 7 shows the presence of significant differences in seasonal precipitation and temperature trends in recent 13 years. Spatial characteristics of seasonal temperature shows variation of mainly significant increasing trend of warming in whole Qinghai Province, while spatial characteristics of precipitation shows decreasing trend in most of the parts of Qinghai Province. Table 3 shows a significant positive relationship between mean winter-NDVI and mean winter precipitation at the $0.01 \%$ significance level, correlation coefficient 0.256 with $\mathrm{P}$ value 0.00 , also there is a significant positive relationship between mean winter-NDVI and mean winter temperature at the $0.01 \%$ significance level, correlation coefficients 0.190 with $P$ value 0.00 . There is a significant positive relationship between mean spring-NDVI and mean spring precipitation at the $0.01 \%$ significance level, correlation coefficients 0.630 with $\mathrm{p}$ value 0.00 , while there is no significant difference between mean spring-NDVI and mean spring temperature. A significant difference is found between mean summer-NDVI and mean summer precipitation at $0.01 \%$ significance level, correlation coefficients 0.638 with $\mathrm{P}$ value 0.00 , while there is a sig-

Table 3. Correlation coefficients of NDVI with climate data by using SPSS software in Qinghai Province over the period of 2001-2013.

\begin{tabular}{cccc}
\hline & Correlation & Pearson correlation & P value, Sig. (2-tailed) \\
\hline 1 & Winter-NDVI with precipitation & $0.256^{* *}$ & 0.000 \\
2 & Winter-NDVI with temperature & $0.190^{* *}$ & 0.000 \\
3 & Spring-NDVI with precipitation & $0.630^{* *}$ & 0.000 \\
4 & Spring-NDVI with temperature & 0.066 & 0.268 \\
5 & Summer-NDVI with precipitation & $0.638^{* *}$ & 0.000 \\
6 & Summer-NDVI with temperature & $-0.216^{* *}$ & 0.000 \\
7 & Autumn-NDVI with precipitation & $0.734^{* *}$ & 0.000 \\
8 & Autumn-NDVI with temperature & 0.080 & 0.177 \\
9 & Mean-NDVI with precipitation & $0.698^{* *}$ & 0.000 \\
10 & Mean-NDVI with temperature & -0.002 & 0.975 \\
\hline
\end{tabular}

${ }^{* *}$ Correlation is significant at the 0.01 level (2-tailed); ${ }^{*}$ Correlation is significant at the 0.05 level (2-tailed). 

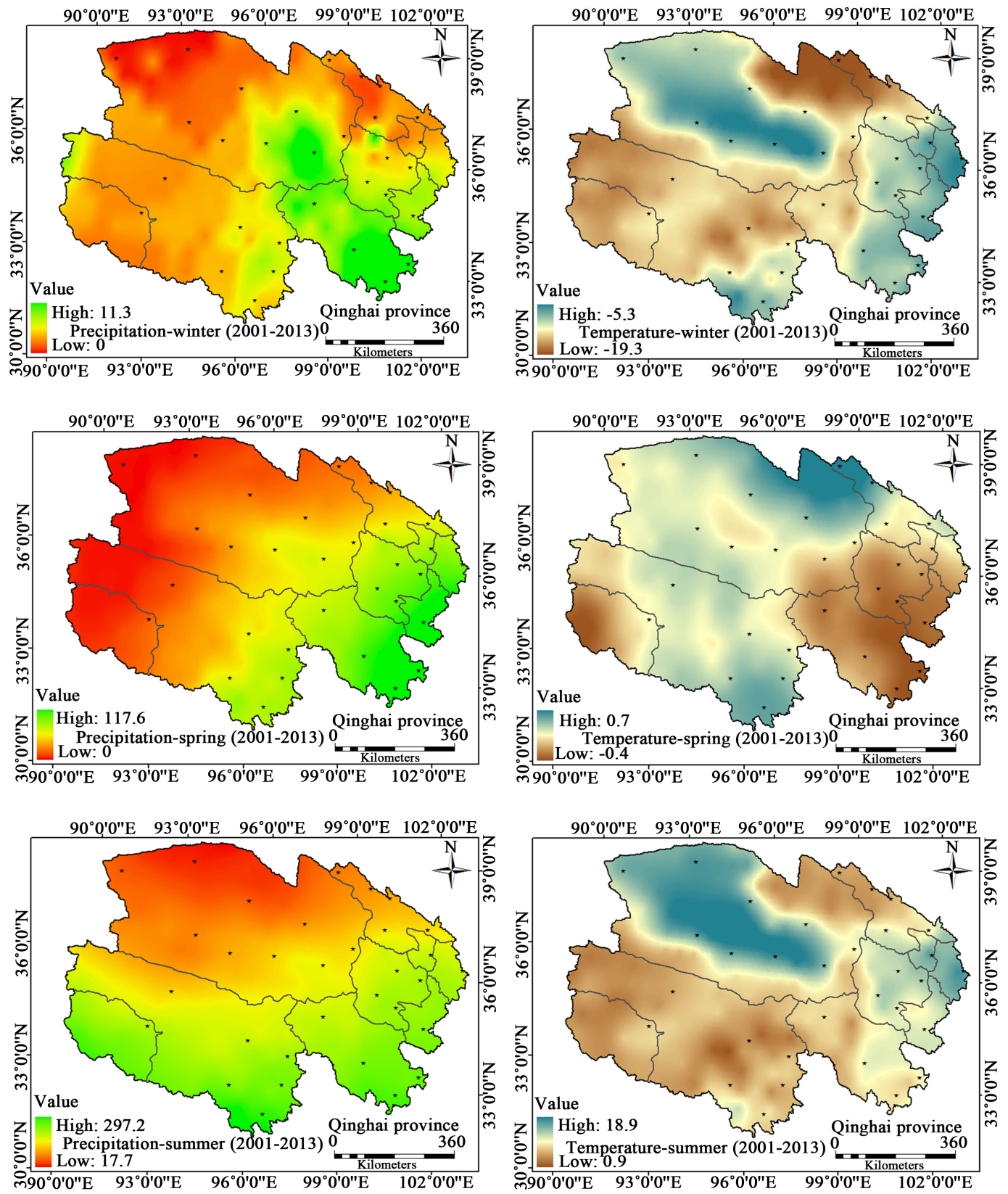

$90^{\circ} 0^{\prime} 0^{\prime \prime} \mathrm{E} \quad 93^{\circ} 0^{\prime} 00^{\prime \prime} \mathrm{E} \quad 96^{\circ} 0^{\prime} 0^{\prime \prime} \mathrm{E} \quad 99^{\circ} 0^{\prime} 00^{\prime \prime} \mathrm{E} \quad 102^{\circ} 0^{\prime} \mathrm{O}^{\prime \prime} \mathrm{E}$

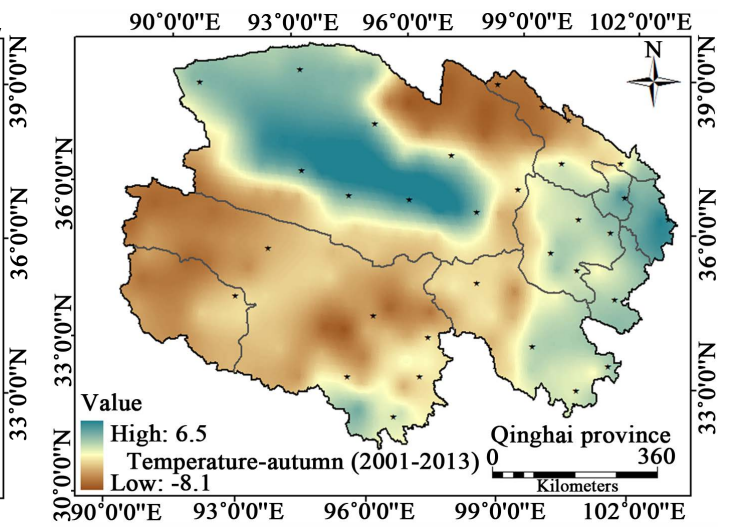

Figure 7. Spatial and temporal distribution of the mean seasonal trend of temperature and precipitation for the past 13 years (2001-2013) in Qinghai Province. 
nificant negative relationship between mean summer-NDVI and mean summer temperature at 0.01 , correlation coefficients -0.216 with $\mathrm{P}$ value 0.00 . There is a significant positive relationship between mean autumn-NDVI with mean autumn precipitation at the $0.01 \%$ significance level, correlation coefficients 0.734 with $\mathrm{P}$ value 0.00 , while there is no significant difference between mean autumn-NDVI and mean autumn temperature.

\subsection{Correlation of NDVI with Climate Factors}

In order to analyze the relationship between high and low vegetation cover and climatic factors in Qinghai Province, we utilize the mean annual precipitation and temperature of 288 sites in recent 13 years. Using correlation analysis method, grid related calculations are obtained in ArcGIS v 10.2 Software, as shown in Figure 8. Table 3 shows the presence of a significant positive relationship between the mean annual-NDVI and mean annual precipitation at the $0.01 \%$ significance level, correlation coefficients 0.698 with $\mathrm{P}$ value 0.00 , while there is no significant difference between the mean annual-NDVI with mean temperature. To test the correlation between the vegetation cover and annual precipitation and temperature, it is divided into eight grades according to the principle of division of significance test different threshold point. Table 4 shows the statistics of correlation coefficient between mean annual-NDVI and climate data factor in Qinghai Province over the period of 2001-2013. Correlation coefficient between mean annual-NDVI and precipitation is significant negative in $0.3 \%$ of total area, high negative in $0.5 \%$ of total area, moderate negative in $3.9 \%$ of total area and low negative in $44.8 \%$ of the total area. While low positive correlation, moderate positive correlation, highly correlated and significant positive correlation is: $46.0 \%, 3.8 \%, 0.5 \%$ and $0.2 \%$ of the total area, respectively. Correlation coefficient between mean annual-NDVI and temperature is: significant negative correlation, high negative correlation, moderate negative correlation and low negative correlation: $0.4 \%, 0.7 \%, 6.3 \%$ and $61.8 \%$ of the total area, respectively.

Table 4. The statistics of the correlation coefficient between mean annual-NDVI and climate data factor in Qinghai Province over the period of 2001-2013.

\begin{tabular}{|c|c|c|c|c|c|c|}
\hline & \multirow{2}{*}{ Category } & \multirow{2}{*}{$\begin{array}{c}\text { Correlation } \\
\text { range }\end{array}$} & \multicolumn{2}{|c|}{ Precipitation } & \multicolumn{2}{|c|}{ Temperature } \\
\hline & & & Area $\mathrm{Km}^{2}$ & Area \% & Area $\mathrm{Km}^{2}$ & Area \% \\
\hline 1 & A significant negative correlation & $<-0.03$ & 2352.9 & 0.3 & 2966.6 & 0.4 \\
\hline 2 & High negative correlation & $-0.03--0.02$ & 3686.4 & 0.5 & 5330.9 & 0.7 \\
\hline 3 & Moderate negative correlation & $-0.02--0.01$ & $27,984.7$ & 3.9 & $44,883.1$ & 6.3 \\
\hline 4 & Low negative correlation & $-0.01-0.00$ & $320,608.6$ & 44.8 & $442,360.1$ & 61.8 \\
\hline 5 & Low positive correlation & $0.00-0.01$ & $329,231.6$ & 46.0 & $205,962.7$ & 28.8 \\
\hline 6 & Moderate positive correlation & $0.01-0.02$ & $26,946.0$ & 3.8 & $12,180.3$ & 1.7 \\
\hline 7 & Highly correlated & $0.02-0.03$ & 3391.5 & 0.5 & 1422.4 & 0.2 \\
\hline \multirow[t]{2}{*}{8} & A significant positive correlation & $>0.03$ & 1622.0 & 0.2 & 717.6 & 0.1 \\
\hline & Total & & $715,823.8$ & 100.0 & $715,823.8$ & 100.0 \\
\hline
\end{tabular}



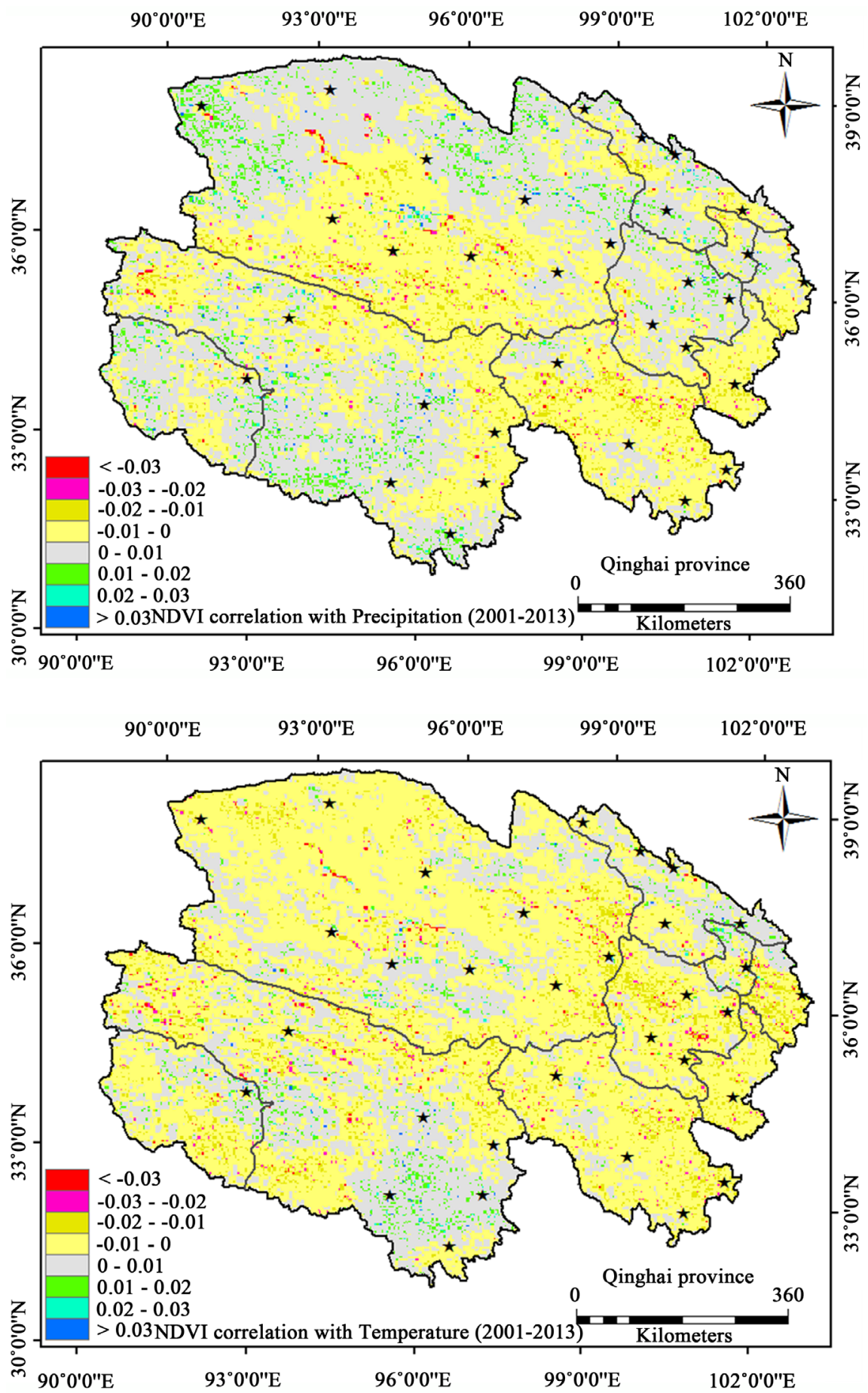

Figure 8. Correlation between mean annual-NDVI and climate factors in Qinghai Province over the period of 2001-2013.

While low positive correlation, moderate positive correlation, highly correlated and significant positive correlation is: $28.8 \%, 1.7 \%, 0.2 \%$ and $0.1 \%$ of the total area, respectively.

It is clear from the findings that NDVI has high relationship with precipitation as compared to temperature. Hence, it is deduced that precipitation is the controlling climate factor of NDVI in Qinghai Province of China. 


\section{Conclusions}

Findings of this study shows that when drought occur due to decrease in precipitation, it can reduce the natural vegetation and crop covers as well as livestock production and consequently influence the economy. In recent years, Qinghai Province is observing intensified climate warming and decrease of precipitation, arid zone showed frequent trend in recent years, affecting the region more widely. The economic losses caused by drought are also growing rapidly in the region; therefore, need to take comprehensive measures, a common response of whole society, principle of the whole society to participate fully in the role of the government and drought relief headquarters. Qinghai Province has a growing agricultural sector and a keen desire to seek policy options that will increase incomes for the many lower-income households involved in agriculture and other related economic activities.

This study recommends additional investigations to discover the crops suitable in the Qinghai Province during drought conditions, which can be used for crop modeling for appropriate agricultural and water management during drought. Further studies on drought prediction under future climate scenarios in Qinghai Province using methods presented in this study will be part of the future direction of this study. The influences of drought in Qinghai Province, such as the shortage of food led to humanitarian disaster including the risk of death, injury and diseases during the famines. A succession of dry years resulted in severe social and economic impacts. Reduced moisture content of soil led to direct effect on agricultural production, resulting poor plant growth, or even wither and significantly reduced crop yield. Decreasing trend in grassland is causing declining of unpalatable forbs for livestock and consequently leading to direct economic loss. For example: Mitigation activities need to be implemented in an integrated way and take a long-term view, rather than involving short-term, stand-alone projects. Institutions working on environmental issues must need to coordinate with each other.

\section{Acknowledgements}

The present research is supported by the National Natural Science Foundation of China (Grant no. 41471058 and 41641003), the NSFC project (grant number: 91425303), and the SKLCS funding (SKLCS-ZZ-2017).

\section{References}

[1] IPCC (2013) Working Group I Contribution to the Fifth Assessment Report of the Intergovernmental Panel on Climate Change The Physical Science Basis, Summary for Policymakers, Climate Change 2013.

https://www.ipcc.ch/pdf/assessment-report/ar5/wg1/WGIAR5_SPM_brochure_en.p df

[2] Piao, S., Cui, M., Chen, A., Wang, X., Ciais, P., Liu, J. and Yanhong, T. (2011) Altitude and Temperature Dependence of Change in the Spring Vegetation Green-Up Date from 1982 to 2006 in the Qinghai-Xizang Plateau. Agricultural and Forest Meteorology, 151, 1599-1608. 
http://www.sciencedirect.com/science/article/pii/S0168192311002097

[3] Lewis, S.L. (2006) Tropical Forests and the Changing Earth System. Philos. Trans. R. Soc. B: Biol. Sci, 361, 195-210.

https://www.ncbi.nlm.nih.gov/pmc/articles/PMC1626535/

[4] Wang, X.J., Zhang, J.Y., Shamsuddin, S., Amgad, E., He, R.M., Bao, Z.X. and Ali, M. (2012) Water Resources Management Strategy for Adaptation to Droughts in China. Mitigation and Adaptation Strategies for Global Change, 17, 923-937. https://doi.org/10.1007/s11027-011-9352-4

[5] Lu, E., Luo, Y., Zhang, R., Wu, Q. and Liu, L. (2011) Regional Atmospheric Anomalies Responsible for the 2009-2010 Severe Drought in China. Journal of Geophycal Research, 116, D21.

http://onlinelibrary.wiley.com/doi/10.1029/2011JD015706/abstract

[6] Lu, E., Cai, W., Jiang, Z., Zhang, Q., Zhang, C., Higgins, R.W. and Halpert, M.S., (2014) The Day-to-Day Monitoring of the 2011 Severe Drought in China. Climate Dynamics, 43, 1-9. https://doi.org/10.1007/s00382-013-1987-2

[7] Wang, A.H., Lettenmaier, D.P. and Sheffield, J. (2011) Soil Moisture Drought in China, 1950-2006. Journal of Climate, 24, 3257-3271.

https://doi.org/10.1175/2011JCLI3733.1

[8] Yu, S.Q. (2005) The Change of Daily Temperature during Recent 50 Years in China. Journal of Applied Meteorological Science, 16, 787-793. http://www.oriprobe.com/journals/yyqxxb/2005_6.html

[9] Wilhite, D.A. (2000) Drought as a Natural Hazard: Concepts and Definitions. DigitalCommons@Universityof Nebraska - Lincoln. Chapter, 1, 1-18. https://pdfs.semanticscholar.org/978b/179885ad9cd08da8ef466ca717425a4eb82c.pd $\underline{\mathrm{f}}$

[10] FAO (2005) Food Agriculture Organization of the United Nations. Livestock Information, Sector Analysis and Policy Branch. AGAl, July.

http://www.fao.org/ag/AGAInfo/resources/en/publications/sector_briefs/lsb_NPL.p df

[11] Yang, F. and Liu, L. (2012) Study on Occurrence Pattern and Trend of Drought in East Qinghai Province. Arid Zone Research, 29, 284-288. http://en.cnki.com.cn/Article_en/CJFDTOTAL-GHQJ201202014.htm

[12] Haberl, H. (1997) Human Appropriation of Net Primary Production as an Environmental Indicator: Implications for Sustainable Development. Ambio, 26, 143-146. https://www.jstor.org/stable/4314572?seq=1\#page_scan_tab_contents

[13] Yan, L., Li, L. and Liu, Y. (2013) How to Comprehensively Evaluate the Economic Loss Due to Drought and Snow Disaster in Qinghai Pastoral Areas. Journal of Glaciology and Geocryology, 35, 662-668.

[14] The World Bank (2007) China: Innovations in Agricultural Insurance. Promoting Access to Agricultural Insurance for Small Farmers. Sustainable Development, East Asia \& Pacific Region Finance and Private Sector Development. The World Bank, Washington DC. http://globalagrisk.com/Pubs/2007_WB_ChinaAgInsurance_may.pdf

[15] Editorial Board of China Agriculture Yearbook (2012) China Agriculture Yearbook. China Agriculture Press, Beijing. http://english.agri.gov.cn/service/ayb/201411/P020141104528458939328.pdf

[16] Yagoub, Y.E., Li, Z.Q., Musa, O.S., Anjum, M.N., Wang, F.T., Xu, C.H. and Bo, Z. (2017) Investigation of Vegetation Cover Change in Sudan by Using Modis Data. Journal of Geographic Information System, 9, 279-292. 
http://file.scirp.org/pdf/JGIS_2017060913481090.pdf

https://doi.org/10.4236/jgis.2017.93017

[17] Editorial Board of China Agriculture Yearbook (2014) China Agriculture Yearbook. China Agriculture Press, Beijing.

http://www.stats.gov.cn/tjsj/ndsj/2014/indexeh.htm

[18] Stow, D., Petersen, A., Hope, A., Engstrom, R. and Coulter, L. (2006) Greenness Trends of Arctic Tundra Vegetation in the 1990s: Comparison of Two NDVI Datasets from NOAA AVHRR Systems. International Journal of Remote Sensing, 28, 4807-4822. http://www.tandfonline.com/doi/abs/10.1080/01431160701264284 https://doi.org/10.1080/01431160701264284

[19] Chen, B.X., Zhang, X.Z., Tao, J., Wu, J.S., Wang, J.S., Shi, P.L., Zhang, Y.J. and Yu, C.Q. (2014) The Impact of Climate Change and Anthropogenic Activities on Alpine Grassland over the Qinghai-Tibet Plateau. Agricultural and Forest Meteorology, 189-190, 11-18. https://doi.org/10.1016/j.agrformet.2014.01.002

Submit or recommend next manuscript to SCIRP and we will provide best service for you:

Accepting pre-submission inquiries through Email, Facebook, LinkedIn, Twitter, etc. A wide selection of journals (inclusive of 9 subjects, more than 200 journals)

Providing 24-hour high-quality service

User-friendly online submission system

Fair and swift peer-review system

Efficient typesetting and proofreading procedure

Display of the result of downloads and visits, as well as the number of cited articles

Maximum dissemination of your research work

Submit your manuscript at: http://papersubmission.scirp.org/

Or contact jgis@scirp.org 